\title{
Radiation safety design for SSRL storage ring
}

\author{
Hesham Khater , James Liu, Alberto Fasso, Alyssa Prinz and Sayed Rokni \\ Radiation Protection Department, Stanford Linear Accelerator Center (SLAC), \\ 2575 Sand Hill Road, Menlo Park, CA 94025, USA
}

\begin{abstract}
In 2003, the Stanford Synchrotron Radiation Laboratory (SSRL) has upgraded its storage ring to a $3^{\text {rd }}$ generation storage ring (SPEAR3). SPEAR3 is deigned to operate at $500 \mathrm{~mA}$ stored beam current and $3 \mathrm{GeV}$ energy. The 234-meter circumference SPEAR3 ring utilizes 60-cm-thick concrete lateral walls, 30-cm-thick concrete roof, as well as $60-\mathrm{cm}$ or 90 -cm-thick concrete ratchet walls. A total of $3.5 \times 10^{15} \mathrm{e}^{-/ y}$ will be injected into the ring with an injection power of $4 \mathrm{~W}$ and an injection efficiency of $75 \%$. Normal beam losses occur due to both injection and stored beam operations in the total of 20 low loss as well as 3 high loss limiting apertures. During the 6-minutes injection period, an instantaneous power loss of $0.05 \mathrm{~W}$ occurs at each low loss aperture. When averaged over the operational year, the loss of both the injection and stored beams is equivalent to an average loss of $2 \mathrm{~mW}$ at each low loss aperture. On the other hand, the average losses in the high loss apertures are $16 \mathrm{~mW}$ for the injection septum, $47 \mathrm{~mW}$ for the beam abort dump, and $13 \mathrm{~mW}$ for the ring stoppers. The shielding requirements for losses in the new ring were based on a generic approach that used both FLUKA Monte Carlo particle generation and transport code and empirical computer codes and formulae.
\end{abstract}

Keywords: SPEAR3; synchrotron radiation; storage ring design

\section{Introduction}

In 2003, SSRL (Stanford Synchrotron Radiation Laboratory) upgraded its storage ring to SPEAR3 (3 GeV and $500 \mathrm{~mA}$ ), a $3^{\text {rd }}$ generation storage ring. SSRL is a division of SLAC (Stanford Linear Accelerator Center) and, thus, the SLAC safety policies and practices apply to SPEAR3 design. The 234-m-circumference SPEAR3 ring 
inherited the existing SPEAR2 concrete ring walls and roof (60-cm-thick lateral wall, 30-cm-thick roof, as well as 60 -cm or 90-cm-thick ratchet wall; at the injection section, the outer lateral wall is 120 -cm-thick and the roof is 60 cm-thick). Currently there are 16 ratchet walls with 11 operating main beamlines around the outer ring wall.

SPEAR3 has a thin copper antechamber vacuum chamber design and 36 C-shaped gradient dipoles (opening toward the outer lateral wall), instead of the H-shaped bends for SPEAR2 (3 GeV and $100 \mathrm{~mA}$ ). There are three normal high loss apertures (septum, stored beam abort dump and ring stoppers) and 20 low loss apertures (8high dispersion quadrupoles, 7 insertion devices, 2 synchrotron masks, and 3 injection kickers) around the ring. It is expected that these apertures will have local shielding to accommodate the increase of stored current. During SPEAR3 operation, the stored beam current will be increased from $100 \mathrm{~mA}$ (SPEAR2) to $500 \mathrm{~mA}$. This significant increase in the stored beam current requires reexamining the shielding of all normal beam loss points in the SPEAR3 ring. Radiation shielding calculations were performed to identify the amount of shielding required under the assumption of SPEAR3 beam loss conditions. The radiation dose limits for the different beam loss conditions are listed in Table 1. The normal beam loss is based on available information regarding future SPEAR3 operation (Corbett, J. et al., 2001). During mis-steering conditions, the maximum injected beam power allowed by the Average Current Monitors (ACMs) in the Booster To SPEAR (BTS) line is $5 \mathrm{~W}$. On the other hand, during a system failure (failure of the ACMs), the maximum credible beam power is $45 \mathrm{~W}$. As shown in Table 1, normal beam losses dictate the shield design.

In this paper, the following radiation safety design and requirements for the SPEAR3 ring are presented:

1) Beam loss scenarios which includes: a) annual normal beam losses of both the injected and stored beam in all identified apertures in the ring, and b) Mis-steered loss of the Allowed Injection Beam Power of $5 \mathrm{~W}\left(\mathrm{P}_{\mathrm{a}}\right)$ at any point in the ring chamber and frontend components.

2) Shielding design limits at SLAC and the design criteria used for SPEAR3 ring.

3) Shielding requirements for the lateral wall and roof.

4) Generic shielding methodology and requirements for the ratchet wall.

\section{Beam loss scenarios}

The beam loss scenarios considered in this analysis are summarized as follows: 
1) Normal beam losses around the ring during both the injection and stored beam operations (Corbett, J., 2001a). A total of 23 limiting apertures (8 QFCs, 7 insertion devices, 1 SR masks near West Pit, 3 injection kickers, injection septum, stored beam abort dump, and ring stoppers) around the ring were identified as normal beam loss points. Figure 1 shows all limiting apertures in the SPEAR3 ring. The septum, beam abort dump and ring stoppers (used to kill the stored beam) are the three high loss points, while the remaining 20 apertures are low loss points. A total of $3.5 \times 10^{15} \mathrm{e}^{-/ y}$ will be injected into the ring with an injection power of $4 \mathrm{~W}(3 \mathrm{GeV}, 10 \mathrm{~Hz})$ and an estimated injection efficiency of 75\%. During the 6-min injection period, an instantaneous power loss of $0.05 \mathrm{~W}$ (with an added safety factor of two) occurs at each low loss aperture, as well as at the beam abort dump. On the other hand, injections loss in the septum is $0.5 \mathrm{~W}$ and there is no injection loss in the ring stoppers (they remain open during injection). When averaged over a period of $7200 \mathrm{~h} / \mathrm{y}$, the annual loss of both the injection and stored beams is equivalent to an average loss of $2 \mathrm{~mW}$ at each low loss aperture. The average loss is 47 $\mathrm{mW}$ at the beam abort dump, $16 \mathrm{~mW}$ (with an added safety factor of 2 to account for uncertainty in the estimated injection efficiency) at the septum, and $13 \mathrm{~mW}$ at the ring stoppers.

2) Mis-steered loss of the Allowed Injection Beam Power of $5 \mathrm{~W}\left(\mathrm{P}_{\mathrm{a}}\right)$ at any point in the ring antechamber at a maximum horizontal angle of $1^{\circ}$ (Corbett, J., 2002).

3) Mis-steered loss of power $P_{a}$ at any point in the frontend section.

4) Loss of the power $P_{a}$ at a point in the frontend during system failure conditions, e.g., movable mask or an injection stopper fails to be inserted into the beamline during injection.

Figure 2 shows the radiation safety items located in a frontend, consisting of a copper movable mask (MM), a lead/polyethylene (15-cm Pb and 15-cm PE) collimator, two beamline injection stoppers (lead or heavimet) interlocked to be inserted into the beamline with MM during injection, a lead/polyethylene $(30-\mathrm{cm} \mathrm{Pb}$ and $15-\mathrm{cm}$ $\mathrm{PE}$ ) shielding in the ratchet wall hole, and the 15- $\mathrm{cm} \mathrm{Pb}$ and 15- $\mathrm{cm}$ PE shadow walls placed at strategic locations near the ring chamber. The shadow walls are primarily used to intercept the secondary radiation generated from beam losses in the ring chamber that may otherwise pass through the beampipe hole in the ratchet wall. 


\section{Shielding design limits at SLAC and criteria used for SPEAR3 ring}

The shielding design limits at SLAC are shown in Table 2. The shielding design limit for normal beam losses is generally $10 \mathrm{mSv} / \mathrm{y}$ for Radiologically Controlled areas (RCA) and $1 \mathrm{mSv} / \mathrm{y}$ for non-RCA (an occupancy of $2000 \mathrm{~h} / \mathrm{y}$ is generally assumed). For abnormal beam losses, the limit is $4 \mathrm{mSv} / \mathrm{h}$ for mis-steered beam and $0.25 \mathrm{~Sv} / \mathrm{h}$ for system failure cases. Active devices should be present to detect and terminate abnormal beam losses (except stored beam losses). Based on the SLAC limits and practical considerations for SSRL, the criteria used for SPEAR3 ring shielding design under three types of beam loss scenarios are given in Table 3. The shielding design criterion for normal beam losses is set at $1 \mathrm{mSv}$ per $1000 \mathrm{~h}$, based on a maximum occupancy of $700 \mathrm{~h} / \mathrm{y}$ for SSRL users on the floor. The shielding design value outside the outer ring wall for a normal beam loss of $2 \mathrm{~mW}$ at a low loss aperture is $1 \mu \mathrm{Sv} / \mathrm{h}$. This is equivalent to a Normalized Dose Limit (NDL) of $0.5 \mathrm{mSv} / \mathrm{W} . \mathrm{h}$. The corresponding shielding design value outside the inner ring wall (which is occupied infrequently) is $8 \mathrm{mSv}$ per $2000 \mathrm{~h}$ (i.e., 4 $\mu \mathrm{Sv} / \mathrm{h}$ ). The design value on top of roof is $30 \mathrm{mSv}$ per $2000 \mathrm{~h}$ (average $15 \mu \mathrm{Sv} / \mathrm{h}$ ). The roof is fenced off and administratively controlled for no access.

For mis-steered beam losses, the limit is raised to $12 \mathrm{mSv} / \mathrm{h}$ outside the ring wall (equivalent to a NDL of $2.4 \mathrm{mSv} / \mathrm{W} . \mathrm{h}$ for $5 \mathrm{~W}$ loss at any point in the ring), because of the use of active Beam Containment System (BCS) devices around the ring (e.g., 18 interlocked radiation detectors called Beam Shut Off Ion Chambers (BSOICs) outside the outer ring wall and four Long Ion Chambers (LIONs) inside the ring). Since the roof is to be fenced off, the mis-steered criterion for the roof was set at $30 \mathrm{mSv} / \mathrm{h}$. For the system failure beam losses, the SPEAR3 ring design criterion is $0.25 \mathrm{~Sv} / \mathrm{h}$. The Maximum Credible Injection Beam Power $\left(\mathrm{P}_{\mathrm{m}}\right)$ is $45 \mathrm{~W}$ (a system failure of all six ACMs in Linac and the BTS lines). This is equivalent to a NDL of $5.55 \mathrm{mSv} / \mathrm{W} . \mathrm{h}$. Therefore, normal beam losses dictate the shielding design.

Currently, there are no SLAC limits for the instantaneous dose rates during the short injection periods. However, the maximum dose rates experienced during SPEAR2 injection periods are less than $10 \mu \mathrm{Sv} / \mathrm{h}$ outside the outer lateral wall, $50 \mu \mathrm{Sv} / \mathrm{h}$ outside the inner wall, and $150 \mu \mathrm{Sv} / \mathrm{h}$ on the roof. The same dose rates were adopted as SPEAR3 design goals during injection. Note that the ratio between injection beam loss and average beam loss at a low loss aperture is $25(0.05 \mathrm{~W}$ over $0.002 \mathrm{~W})$. Thus, when the normal loss design criterion is $1 \mu \mathrm{Sv} / \mathrm{h}$, it is expected that the dose rate during injection outside the outer lateral wall could be $\sim 25 \mu \mathrm{Sv} / \mathrm{h}$. In any case, the 
radiation level during the injection period should be less than $50 \mu \mathrm{Sv} / \mathrm{h}$. Otherwise, Radiation Area (RA) control would be needed.

\section{Shielding and safety requirements}

The dose calculations were performed using the analytical SHIELD11 code (Nelson, W. and Jenkins, T., 2005) for thick target cases and the FLUKA Monte Carlo code (Fasso, A. et al., 2001) for thin target cases. Since the thin target results could be significantly affected by any change in the estimated low beam loss (2 $\mathrm{mW})$ or the incident beam angle on the thin target (change in the effective thickness of the target (Mao, X. et al., 2000)), a safety factor of three was added to the FLUKA results.

\subsection{Shielding of Lateral Wall and Roof}

\subsubsection{Normal and Abnormal Beam Losses in Ring Chamber}

The shielding requirements (Khater, H. et al., 2003), for lateral wall and roof from normal and abnormal beam losses in the ring chamber are summarized in Table 4 (shielding requirements) and Table 5 (dose rates). For example, Table 4 shows that the injection septum is $160-\mathrm{cm}, 75-\mathrm{cm}$, and $100-\mathrm{cm}$ from the inner surface of the 120 cm-thick outer wall, 60-cm-thick inner wall, and 60-cm-thick roof, respectively. The shielding required is 0-cm, 10$\mathrm{cm} \mathrm{Fe}$, and 10-cm Fe on the side of outer wall, inner wall, and roof, respectively. The length of shield should cover $45^{\circ}$ backward of the first beam loss point and $45^{\circ}$ forward of the last beam loss point inside the septum. Table 5 shows that the resulting doses (for $16 \mathrm{~mW}$ loss) are $0.4 \mathrm{mSv}$ over $1000 \mathrm{~h} / \mathrm{y}$, as well as $2.1 \mathrm{mSv}$ and $4.8 \mathrm{mSv}$ over $2000 \mathrm{~h} / \mathrm{y}$, outside the outer wall, inner wall, and roof, respectively. The corresponding mis-steered dose rates (for 5 $\mathrm{W}$ loss) at the outer wall, inner wall and roof are $0.12,0.33$, and $0.73 \mathrm{mSv} / \mathrm{h}$, respectively.

Similar to the injection septum, the other two high normal beam loss points (stored beam abort dump and ring stoppers) also need additional shielding. The-highest inner ring dose is due to the beam abort dump (7.95 $\mathrm{mSv} / 2000 \mathrm{~h})$. For $2 \mathrm{~mW}$ loss at a low loss aperture, Tables 4 and 5 show that 5-cm-thick Fe or 2.5-cm-thick Pb local shield is needed. Based on FLUKA simulations (Khater H. et al., 2004), the length of the local shielding is 30-cm upstream and 60-cm downstream of beam loss point (mid point of a QFC or the beginning and/or the end of an ID). 
The height should cover a vertical angle of $\pm 30^{\circ}$ to the outer lateral wall. Section G4 of the ring is located immediately downstream of the septum. According to experience from SPEAR2 and other SR facilities, this section tends to have more normal beam losses than other ring sections. Therefore, it was assumed that Section G4 has an average normal beam loss of $4 \mathrm{~mW}$.

In addition to normal beam losses in apertures, abnormal beam loss of $5 \mathrm{~W}$ could occur at any point in the ring chamber. The worst case is that the $3 \mathrm{GeV}$ injection beam is mis-steered to hit the thin $0.7-\mathrm{cm} \mathrm{Cu}$ antechamber wall with a maximum horizontal angle of $1^{\circ}$ (Corbett, J., 2002). Table 5 shows that the mis-steered loss of $5 \mathrm{~W}$ resulted in dose rates of 5, 2.85, and $28.5 \mathrm{mSv} / \mathrm{h}$ outside the outer wall, inner wall, and roof, respectively. Therefore, no shield for lateral wall and roof is needed for mis-steered beam loss in the ring.

\subsubsection{Mis-steered Injection Beam Loss in the Frontend}

FLUKA simulations (Liu, J. et al., 2003) with frontend geometries for both bend and ID beamlines (similar to Figure 2) were used to calculate the dose rates outside the lateral wall, ratchet wall, and roof. Table 6 shows that, for $3 \mathrm{GeV}$ electron beam hitting the $2^{\circ}$-tilted $\mathrm{Cu}$ movable mask in an ID beamline, the roof has a maximum dose rate of $55.5 \mathrm{mSv} / \mathrm{h}$ at $5 \mathrm{~W}$, which is higher than the limit of $30 \mathrm{mSv} / \mathrm{h}$. The higher than normal dose rate limit was justified by the following 3 arguments: a) the roof is fenced off, b) mis-steered injection beam losses in a frontend are not likely (Corbett, J., 2003), and c) credit for use of active radiation detectors. The corresponding dose rate outside the lateral wall is $10.8 \mathrm{mSv} / \mathrm{h}$.

\subsection{Shielding of Ratchet Wall}

The radiation of concern outside the ratchet wall is the forward peaked photons and neutrons from beam losses in ring chamber or a frontend component. Generic approach for ratchet wall shielding calculation and requirement has been developed. Implementation of safety requirements is reviewed for every ratchet wall via comprehensive ray trace study.

\subsubsection{Normal and Abnormal Beam Losses in Ring Chamber}

FLUKA simulation (Liu, J. et al., 2002) of $3 \mathrm{GeV}$ electron hitting a 0.7-cm Cu antechamber wall at $1^{\circ}$ has been performed. The source terms (normalized photon and neutron dose rates in mSv/W.h at $1 \mathrm{~m}$ ), as well as the 
associated attenuation lengths in concrete, lead, and polyethylene have been calculated as a function of angle relative to the beam direction. With these pre-calculated data, the dose at any angle and shield thickness can be calculated using the information obtained from the ray trace study. The generic shielding requirements for ratchet wall were developed by studying the two worst geometry cases for $60-\mathrm{cm}$ and 90 -cm ratchet walls (i.e., for shortest distance between the ratchet wall and ring source point).

Ray trace studies were performed (Rabedeau, T., 2003) for 16 source points (SA to SK) and 5 dose points outside ratchet walls for the worst in-alcove geometries (OF to OJ). Two heights at a dose point were studied; the ray at median plane (to examine the thickness and width of shadow walls, as well as their locations) and the ray that just skims over the 30-cm-tall shadow wall (to examine the need of lead skirt on top and below every shadow wall). Data sheets using the Excel program (which incorporates the FLUKA calculated source terms and attenuation lengths) were developed to calculate the corresponding dose rates. As an example, Table 7 shows the calculated dose rates outside a $60-\mathrm{cm}$-thick concrete ratchet wall with $2.5-\mathrm{cm} \mathrm{Pb}$ on its inner surface. Note that the source points ID, SE, and SL are normal beam loss points, while the others are mis-steered beam loss points. Some normal loss points generate doses outside ratchet wall that are higher than the limit (NDL $=0.5 \mathrm{mSv} / \mathrm{W}$.h). The 5-cm-thick and 90-cm-long Fe local shielding alongside the aperture, required for normal beam losses, was not considered in these calculations. The actual doses from normal beam losses are acceptable, after the local shield is added (Khater, H. et al., 2003). The mis-steered limit of $2.4 \mathrm{mSv} / \mathrm{W} . \mathrm{h}$ is met in all cases. Similar analysis was performed for the most critical 90-cm-thick concrete ratchet wall. The ray trace study also showed that there are some self-shielding of ring components, particularly when the ray is off the median plane. Since the self-shielding was not considered in the calculations, the safety factor of 3 for the FLUKA results was not applied in this case.

The ratchet wall shielding requirements are summarized in Table 8. The 90-cm-thick concrete ratchet wall effectively shield against beam losses from the ring. The 60-cm-thick ratchet wall needs an additional 2.5-cm-thick $\mathrm{Pb}$ shield. The collimator and shadow walls need to be at least 15-cm Pb and 15-cm-thick PE and 30-cm-tall and their locations should be placed such that all rays from ring chamber to the hole in the ratchet wall are intercepted.

\subsubsection{Mis-steered Injection Beam Loss in the Frontend}

The FLUKA simulations with frontend geometries of $60-\mathrm{cm}$ and $90-\mathrm{cm}$ ratchet walls (similar to Figure 2), as well as SHIELD11 for-thick target cases, were used to calculate dose rates outside the ratchet wall. Some key 
dose results are shown in Table 6. Compared with beam losses of $5 \mathrm{~W}$ in ring chamber, the beam losses of $5 \mathrm{~W}$ in frontend would have demanded an additional 2.5-cm-thick lead wall on the ratchet wall, if the argument of low probability of $5 \mathrm{~W}$ loss in frontends was not accepted.

\subsubsection{Generic Safety Requirements for Frontend Components}

The generic safety requirements for the different frontend components are summarized as follow (Liu, J. et al., 2003):

1) For a minimum distance of $2 \mathrm{~m}$ between the front face of an injector stopper and the outer surface of ratchet wall, a stopper-thickness of 12.7-cm heavimet or 17.8-cm lead is needed for $0^{\circ}$ dose.

2) The minimum distance D1 between the first stopper and the 60-cm ratchet wall outer surface is $6.2 \mathrm{~m}$ and the minimum distance D2 between the front face of the $2^{\text {nd }}$ injector stopper and the outer surface of 60 -cm ratchet wall is $3.1 \mathrm{~m}$. For the $90-\mathrm{cm}$ ratchet wall, the minimum D1 and D2 distances are $3.1 \mathrm{~m}$ and $1.8 \mathrm{~m}$, respectively. This assumed no lead wall on the inner surface of ratchet wall.

3) 30-cm Pb and 15-cm PE filling the hole around the beampipe in the ratchet wall is acceptable.

4) Collimator should be at least $15-\mathrm{cm} \mathrm{Pb}$ and $15-\mathrm{cm} \mathrm{PE}$ and 30-cm-high, same as the shadow wall requirements.

Note that there are five ratchet walls that do not have SR beamlines yet and these beamlines, as well as the unused beam exit points need to be terminated with 10-cm-thick lead (20-cm-wide and 10-cm-high) shielding immediately downstream of the beamline exit point. This is to prevent the beam from hitting and creating a shower in the concrete wall.

\section{Summary}

SSRL implemented the required shielding according to the two phases of operation. Prior to the $1.5 \mathrm{~W} / 100$ mA operation, all normal high loss apertures (septum, beam abort dump and ring stoppers) shielding are implemented, except the 5-cm-Fe shielding alongside the low loss apertures (e.g., QFC, IDs, SR masks, and kickers), which will be implemented prior to the $5 \mathrm{~W} / 500 \mathrm{~mA}$ operation. The maximum annual dose outside the outer lateral wall at locations frequently occupied by users from normal beam losses at any aperture is $0.5 \mathrm{mSv}$ over 
1000 hours. This is to be considered together with the doses from beamline operation, which also has a design criterion of $1 \mathrm{mSv}$ per $1000 \mathrm{~h}$. Finally, the dose rate on the experimental floor during normal injection is $10 \mu \mathrm{Sv} / \mathrm{h}$.

\section{Acknowledgements}

This work was supported by the U. S. Department of Energy contract \# DE-AC02-76SF00515.

\section{References}

Corbett, J. et al., 2001. Electron Beam Loss Estimates for SPEAR3, Stanford Synchrotron Radiation Laboratory (SSRL), SSRL-ENG-NOTE M371.

Corbett, J. et al., 2001a. Electron Beam Loss Estimates for SPEAR3, Stanford Synchrotron Radiation Laboratory (SSRL), SSRL-Eng-Note-M371.

Corbett, J., 2002. Injection beam loss angle in SPEAR3, Stanford Synchrotron Radiation Laboratory (SSRL), SSRL-Eng-Note-M423.

Corbett, J., 2003. Electron Beam Loss due to SPEAR3 Dipole Coil Short, Stanford Linear Accelerator Center (SLAC), SSRL-Eng-Note-M441.

Fasso, A. et al., 2001. Electron-Photon Transport in FLUKA: Status, Proceedings of the Monte Carlo 2000 Conference, Lisbon, A. Kling, F. Barao, M. Nakagawa, L. Tavora, P. Vaz eds., Springer-Verlag Berlinl, p. 955960.

Khater, H. et al., 2003. Shielding of-high loss points in the SPEAR3 ring, Stanford Linear Accelerator Center (SLAC), RP Note 03-02.

Khater, H. et al., 2004. Summary of Shielding of Low-Loss Points in the SPEAR3 Ring (500 mA Operation), Stanford Linear Accelerator Center (SLAC), RP Note 04-26.

Liu, J. et al., 2002. FLUKA Calculations of Source Terms and Attenuation Profiles for Generic Shielding Design of SPEAR3 Ring, Stanford Linear Accelerator Center (SLAC), RP Note 02-20.

Liu, J. et al., 2003. Radiation Safety Design for SPEAR3 Beamline Frontend, Stanford Linear Accelerator Center (SLAC), RP Note 03-01. 
Mao, X. et al., 2000. Summary $90^{\circ}$ Bremsstrahlung Source Term Produced in thick Targets by $50 \mathrm{MeV}$ and $1 \mathrm{GeV}$ electrons, Journal of Nuclear Science and Technology, Supplement 1, p. 212-216.

Nelson, W. and Jenkins, T., 2005. The SHIELD11 Computer Code, Stanford Linear Accelerator Center (SLAC), SLAC-R-737.

Rabedeau, T., 2003. SPEAR3 Beamline in Alcove Radiation Shielding, Stanford Synchrotron Radiation Laboratory (SSRL), SSRL M417, Rev. 1. 


\section{Figure Captions}

Figure 1. Location of physical limiting apertures (loss points) in SPEAR3 ring.

Figure 2. A typical frontend for a SSRL synchrotron radiation beamline, showing five radiation safety items (movable mask, 2 injection stoppers, collimator, lead/polyethylene shadow wall, and lead/polyethylene shielding in the hole of the ratchet wall), in addition to the 60-cm-thick concrete lateral wall and concrete ratchet wall (90-cmthick or 60-cm and 2.5-cm Pb). 
Table 1. Dose Rate Limits for Different Beam loss Scenarios.

\begin{tabular}{|c|c|c|c|}
\hline Operation condition & Dose rate limit & Beam loss scenario & Normalized dose rate limit \\
\hline Normal & $1 \mu \mathrm{Sv} / \mathrm{h}$ & $2 \mathrm{~mW}$ & $0.5 \mathrm{mSv} / \mathrm{Wh}$ \\
\hline Mis-steering & $4 \mathrm{mSv} / \mathrm{h}$ & $5 \mathrm{~W}$ & $0.8 \mathrm{mSv} / \mathrm{Wh}$ \\
\hline System Failure & $0.25 \mathrm{~Sv} / \mathrm{h}$ & $45 \mathrm{~W}$ & $5.56 \mathrm{mSv} / \mathrm{Wh}$ \\
\hline
\end{tabular}


Table 2. Shielding Design Limits at SLAC.

\begin{tabular}{|c|c|c|c|}
\hline Conditions & Normal & Mis-steering & System Failure \\
\hline Radiological Control Area (RCA) & $10 \mathrm{mSv} / \mathrm{y}$ & $4 \mathrm{mSv} / \mathrm{h}$ & $0.25 \mathrm{~Sv} / \mathrm{h}$ \\
\hline Non-RCA & $1 \mathrm{mSv} / \mathrm{y}$ & $4 \mathrm{mSv} / \mathrm{h}$ & $0.25 \mathrm{~Sv} / \mathrm{h}$ \\
\hline
\end{tabular}

* An individual entering a RCA needs to wear a dosimeter. 
Table 3. Shielding Design Criteria for SPEAR3 Ring at 5 W/500 mA.

\begin{tabular}{|c|c|c|c|}
\hline Area & Normal Beam Loss & Mis-steering Loss at $5 \mathrm{~W}$ & Normal Injection $^{3}$ \\
\hline $\begin{array}{c}\text { Outer Ring Wall } \\
\text { (User Side) }\end{array}$ & $\begin{array}{c}1 \mathrm{mSv} / 1000 \mathrm{~h} \\
(1 \mu \mathrm{Sv} / \mathrm{h})^{1}\end{array}$ & $12 \mathrm{mSv} / \mathrm{h}^{2}$ & $10 \mu \mathrm{Sv} / \mathrm{h}$ \\
\hline $\begin{array}{c}\text { Inner Ring Wall } \\
\text { (Less Occupied) }\end{array}$ & $\begin{array}{c}8 \mathrm{mSv} / 2000 \mathrm{~h} \\
(4 \mu \mathrm{Sv} / \mathrm{h})\end{array}$ & $12 \mathrm{mSv} / \mathrm{h}^{2}$ & $50 \mu \mathrm{Sv} / \mathrm{h}$ \\
\hline $\begin{array}{c}\text { Roof } \\
\text { (Fenced and No Access) }\end{array}$ & $\begin{array}{c}30 \mathrm{mSv} / 2000 \mathrm{~h} \\
(15 \mu \mathrm{Sv} / \mathrm{h})\end{array}$ & $30 \mathrm{mSv} / \mathrm{h}$ & $150 \mu \mathrm{Sv} / \mathrm{h}$ \\
\hline
\end{tabular}

1) The criterion of $1 \mathrm{mSv}$ per $1000 \mathrm{~h}$ is set based on a maximum occupancy of $700 \mathrm{~h} / \mathrm{y}$ for SSRL users on experimental floor.

2) In SPEAR3 shielding implementation, the mis-steered limit was raised from 4 to $12 \mathrm{mSv} / \mathrm{h}$. SSRL justified this via the extensive use of BSOICs/LIONs in the ring.

3) The criteria for normal injection are set based on the maximum dose rates experienced during SPEAR2 operation. In SPEAR3 shielding implementation, the dose rates may be up to a factor of 2-3-higher than the SPEAR2 values. 
Table 4. Shielding Requirements for Lateral Walls and Roof for Beam Losses in the Ring Chamber.

\begin{tabular}{|c|c|c|c|c|}
\hline Element & $\begin{array}{l}\text { Outer Ring } \\
\text { Side }\end{array}$ & $\begin{array}{c}\text { Inner } \\
\text { Ring Side }\end{array}$ & Top & $\begin{array}{l}\text { Length and Height } \\
\text { Requirements }\end{array}$ \\
\hline $\begin{array}{c}\text { Injection Septum } \\
\text { (120-cm@160-cm,60-cm@75-cm, } \\
\text { 60-cm@100-cm) }\end{array}$ & 0 & $\begin{array}{l}10-\mathrm{cm} \mathrm{Fe} \\
\text { or } 5-\mathrm{cm} \mathrm{Pb}\end{array}$ & $\begin{array}{l}10-\mathrm{cm} \mathrm{Fe} \\
\text { or } 5-\mathrm{cm} \mathrm{Pb}\end{array}$ & \multirow{5}{*}{$\begin{array}{l}\text { 1) Height should cover } \pm \\
30^{\circ} \text { vertical angles. } \\
\text { 2)For septum and ring } \\
\text { stoppers, the length } \\
\text { requirement is } 45^{\circ} \\
\text { backward of the first } \\
\text { and } 45^{\circ} \text { forward of the } \\
\text { last beam loss points in } \\
\text { a device. } \\
\text { 3)For beam abort dump, } \\
\text { low loss apertures, and } \\
\text { G4 section, the length } \\
\text { requirement is } 30-\mathrm{cm} \\
\text { upstream and } 60-\mathrm{cm} \\
\text { downstream of the } \\
\text { beam loss point. }\end{array}$} \\
\hline $\begin{array}{c}\text { Stored Beam Abort Dump } \\
\text { (120-cm@198-cm, 60-cm@198-cm, } \\
\text { 60-cm@100-cm) }\end{array}$ & 0 & $\begin{array}{c}\text { 7.6-cm Fe } \\
\text { or } 7.6-\mathrm{cm} \mathrm{Pb}\end{array}$ & $\begin{array}{c}\text { 7.6-cm Fe } \\
\text { or } 7.6-\mathrm{cm} \mathrm{Pb}\end{array}$ & \\
\hline $\begin{array}{c}\text { Ring Stoppers } \\
\text { (60-cm@150-cm,60-cm@150-cm, } \\
\text { 60-cm@100-cm) }\end{array}$ & $\begin{array}{c}15-\mathrm{cm} \mathrm{Fe} \\
\text { or } 7.6-\mathrm{cm} \mathrm{Pb}\end{array}$ & $\begin{array}{c}\text { 5-cm Fe } \\
\text { or } 2.5-\mathrm{cm} \mathrm{Pb}\end{array}$ & 0 & \\
\hline $\begin{array}{c}\text { Low Loss Apertures } \\
\text { (60-cm@420-cm,60-cm@75-cm, } \\
\text { 30-cm@100-cm) }\end{array}$ & $\begin{array}{c}\text { 5-cm Fe } \\
\text { or } 2.5-\mathrm{cm} \mathrm{Pb}\end{array}$ & 0 & 0 & \\
\hline $\begin{array}{c}\text { G4 (Downstream of Septum) } \\
\text { (60-cm@420-cm,60-cm@198-cm, } \\
\text { 60-cm@100-cm) }\end{array}$ & $\begin{array}{c}\text { 5-cm Fe } \\
\text { or } 2.5-\mathrm{cm} \mathrm{Pb}\end{array}$ & 0 & 0 & \\
\hline
\end{tabular}


Table 5. Dose Rates outside SPEAR3 Lateral Walls and Roof from Beam Losses in the Ring Chamber. ${ }^{\text {a }}$

\begin{tabular}{|c|c|c|c|c|c|c|c|c|}
\hline Location & $\begin{array}{l}\text { Normal }^{\mathrm{b}} \\
\text { (e/7200h) }\end{array}$ & Outer & Inner & Roof & $\begin{array}{c}\text { Mis- } \\
\text { steering }\end{array}$ & Outer & Inner & Roof \\
\hline $\begin{array}{l}\text { Injection } \\
\text { Septum }\end{array}$ & $\begin{array}{l}8.8 \times 10^{14} \\
(16 \mathrm{~mW})\end{array}$ & 0.4 & 2.1 & 4.8 & $5 \mathrm{~W}$ & 0.12 & 0.33 & 0.73 \\
\hline $\begin{array}{l}\text { Beam } \\
\text { Abort } \\
\text { Dump }\end{array}$ & $\begin{array}{l}2.6 \times 10^{15} \\
(47 \mathrm{~mW})\end{array}$ & 0.95 & 7.95 & 20 & $5 \mathrm{~W}$ & 0.1 & 0.41 & 1 \\
\hline $\begin{array}{l}\text { PPS Ring } \\
\text { Stoppers }\end{array}$ & $\begin{array}{l}7.0 \times 10^{14} \\
(13 \mathrm{~mW})\end{array}$ & 0.7 & 5 & 25 & N/A & & & \\
\hline $\begin{array}{l}\text { Low Loss } \\
\text { Aperture }\end{array}$ & $\begin{array}{c}1.1 \times 10^{14} \\
(2 \mathrm{~mW})\end{array}$ & 0.5 & 2.3 & 2.3 & $5 \mathrm{~W}$ & 1.25 & 2.85 & 28.5 \\
\hline $\begin{array}{c}\text { Section } \\
\text { G4 }\end{array}$ & $\begin{array}{c}2.2 \times 10^{14} \\
(4 \mathrm{~mW})\end{array}$ & 1 & 4.6 & 11 & $5 \mathrm{~W}$ & 1.25 & 2.85 & 6.5 \\
\hline $\begin{array}{c}\text { Straight }^{\mathrm{c}} \\
\text { (0.7-cm } \\
\text { Cu target) }\end{array}$ & N/A & & & & $5 \mathrm{~W}$ & 5 & 2.85 & 28.5 \\
\hline $\begin{array}{l}\text { Dose } \\
\text { Limit }\end{array}$ & & $\begin{array}{c}1 \mathrm{mSv} / \\
1000 \mathrm{~h}\end{array}$ & $\begin{array}{l}8 \mathrm{mSv} / \\
2000 \mathrm{~h}\end{array}$ & $\begin{array}{c}30 \mathrm{mSv} / \\
2000 \mathrm{~h}\end{array}$ & & $\begin{array}{c}12 \\
\mathrm{mSv} / \mathrm{h}\end{array}$ & $\begin{array}{c}12 \\
\mathrm{mSv} / \mathrm{h}\end{array}$ & $\begin{array}{c}30 \\
\mathrm{mSv} / \mathrm{h}\end{array}$ \\
\hline
\end{tabular}

a. Shielding required for these dose rates are shown in Table 4.

b. Annual electron normal loss at each location (5 W allowed injection beam power and $500 \mathrm{~mA}$ operation).

c. Straight sections include the beampipes in bare ID straights and the gap between any two components (like dipoles and quads). 
Table 6. Dose Rates from Abnormal Beam Losses of $5 \mathrm{~W}$ at a Thin Target in SPEAR3 Ring.

\begin{tabular}{|c|c|c|c|}
\hline Dose Location & Beam Loss Location & $\begin{array}{l}\text { Maximum Dose Rate } \\
(\mathrm{mSv} / \mathrm{h} \text { at } 5 \mathrm{~W})\end{array}$ & $\begin{array}{l}\text { Shielding to Meet } \\
\text { the Limit }\end{array}$ \\
\hline Lateral Wall & Frontend & 10.8 & None \\
\hline Roof & Frontend & 55.5 & None \\
\hline \multirow{4}{*}{ Ratchet Wall } & \multirow{2}{*}{ Ring Chamber ${ }^{*}$} & $\begin{array}{c}9 \\
\text { (60-cm ratchet wall) }\end{array}$ & 2.5-cm Pb wall \\
\hline & & $\begin{array}{c}11 \\
\text { (90-cm ratchet wall) }\end{array}$ & None \\
\hline & \multirow{2}{*}{ Frontend } & $\begin{array}{c}18 \\
\text { (60-cm ratchet wall) }\end{array}$ & 2.5-cm Pb wall \\
\hline & & $\begin{array}{c}18 \\
\text { (90-cm ratchet wall) }\end{array}$ & None \\
\hline
\end{tabular}

* The safety factor of 3 was not applied to the FLUKA calculated doses outside ratchet wall from beam losses in ring chamber, due to the credit of self-shielding from ring components was not considered in ray trace study. 
Table 7. Dose Rates outside 60-cm-thick Ratchet Wall with 2.5-cm-thick Pb on the Wall.

\begin{tabular}{|c|c|c|c|}
\hline Dose Point & $\begin{array}{l}\text { Source } \\
\text { Point }\end{array}$ & $\begin{array}{c}\text { Scatter Angle }\left(^{0}\right) \\
\text { (Angle with respect to } \\
\text { Beam direction) } \\
\end{array}$ & $\begin{array}{l}\text { Normalized Dose } \\
\text { (mSv/W.h) }\end{array}$ \\
\hline OF median plane & ID & 5 & 0.7 \\
\hline OF over shadow wall & ID & 5 & 0.7 \\
\hline OG median plane & SL & 57 & 0.005 \\
\hline OG over shadow wall & ID & 2 & 0.55 \\
\hline OH median plane & SL & 54 & 0.14 \\
\hline OH above shadow wall & ID & 2 & 0.55 \\
\hline OI median plane & SL & 49 & 0.05 \\
\hline OI above shadow wall & ID & 2 & 0.55 \\
\hline OJ median plane & SL & 36 & 0.2 \\
\hline OJ above shadow wall & SE & 6 & 1.4 \\
\hline OF median plane & SA & 6 & 0.8 \\
\hline OF over shadow wall & SA & 6 & 0.8 \\
\hline OG median plane & SL & 57 & 0.005 \\
\hline OG over shadow wall & SA & 2 & 0.8 \\
\hline $\mathrm{OH}$ median plane & SA & $<2$ & 0.34 \\
\hline $\mathrm{OH}$ above shadow wall & SB & 6 & 0.9 \\
\hline OI median plane & SK & 35 & 0.14 \\
\hline OI above shadow wall & SB & 4.5 & 1 \\
\hline OJ median plane & SK & 25 & 0.3 \\
\hline OJ above shadow wall & $\mathrm{SH}$ & 7.5 & 1.8 \\
\hline
\end{tabular}


Table 8. Shielding for Concrete Ratchet Wall from Beam Losses in Ring Chamber.

\begin{tabular}{|c|c|}
\hline Component & Shielding Requirement \\
\hline $\begin{array}{c}\text { Lead Wall } \\
\text { added to } \\
\text { Ratchet wall }\end{array}$ & $\begin{array}{c}\text { No lead needed for 90-cm-thick concrete wall. } \\
\text { 2.5-cm-thick Pb needed for 60-cm-thick concrete wall. }\end{array}$ \\
\hline Collimator & \begin{tabular}{c}
$15-\mathrm{cm} \mathrm{Pb}$ and $15-\mathrm{cm}$ PE-thick, 30-cm -tall, 30-cm -wide to cover the beampipe hole in ratchet wall. \\
\hline Shadow Walls
\end{tabular}$\quad$ 15-cm Pb and 15-cm PE-thick, 30-cm-tall to cover the beampipe hole for all rays. \\
\hline Hole Shielding & $30-\mathrm{cm} \mathrm{Pb}$ and 15-cm PE around the beampipe in the ratchet wall. \\
\hline
\end{tabular}




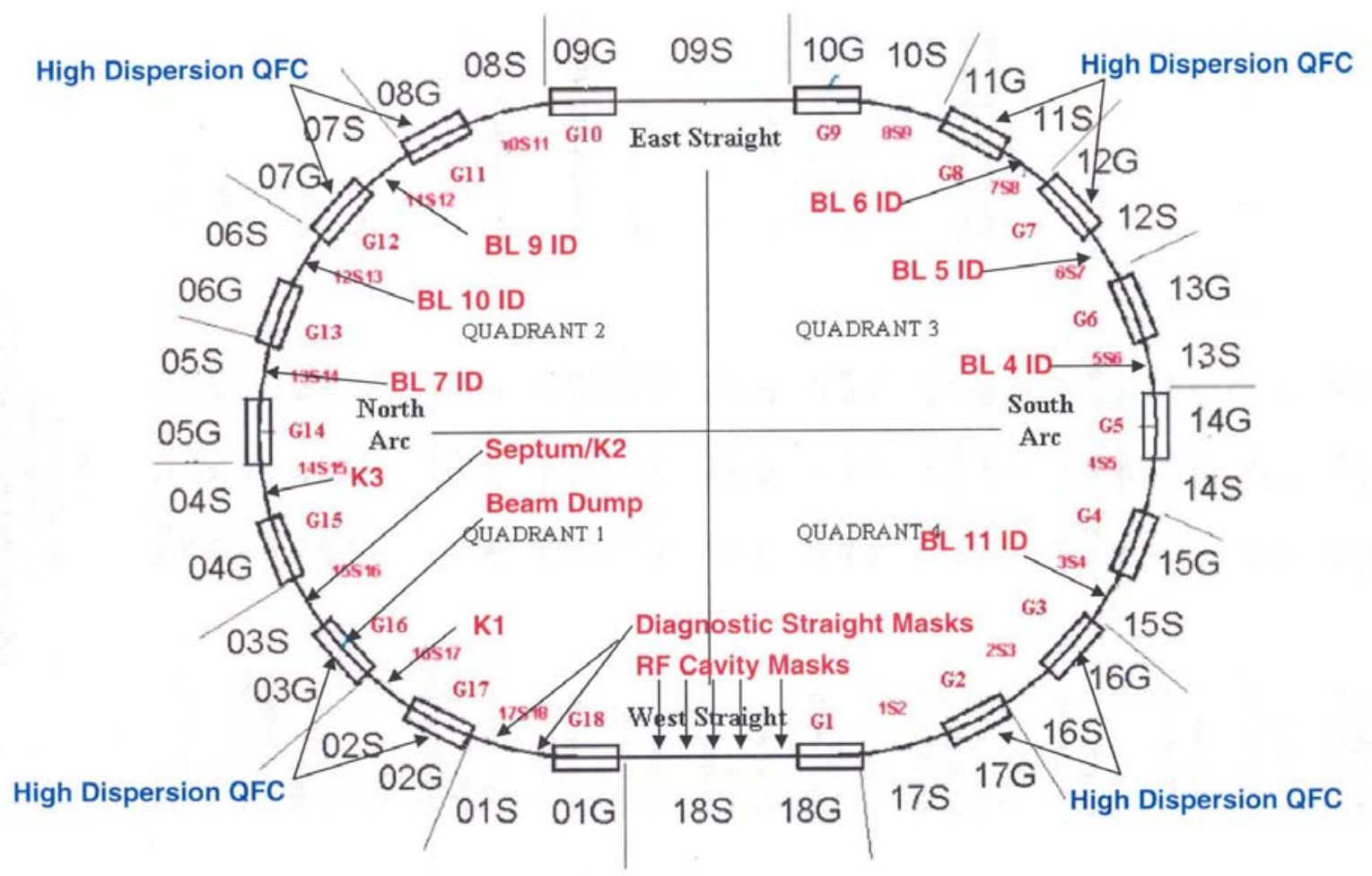

black $=$ SPEAR 3 sector numbering red = SPEAR 2 sector numbering RED BOLD: Limiting Aperture BLUE BOLD: High non-linear dispersion QFC Location 


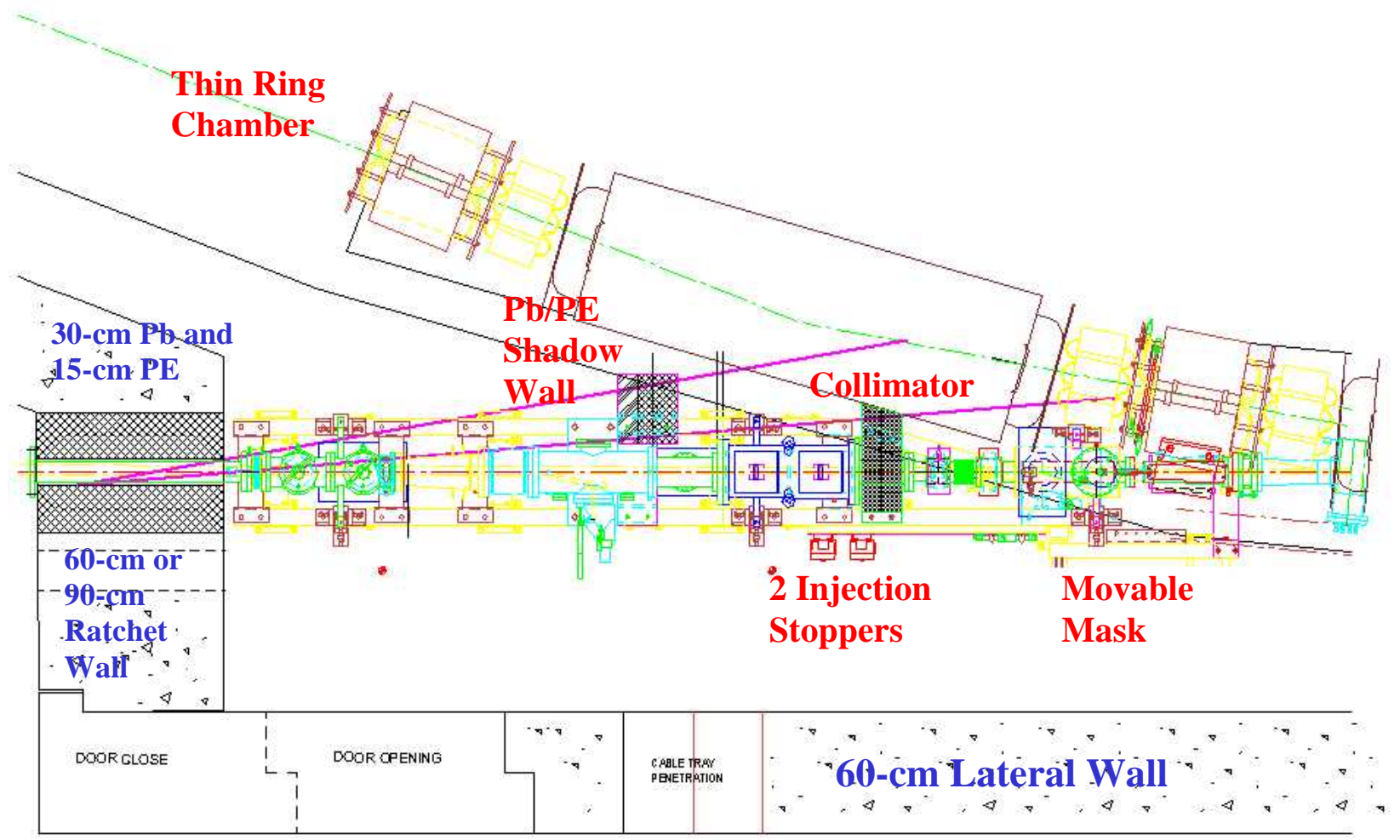

